\title{
Piero's perspective
}

\section{Renaissance painter Piero della Francesca plotted perspective so meticulously and consistently that he was able to make the divine, with its miraculous lack of optical logic, shine out in contrast to the rest of the picture.}

\section{Martin Kemp}

M

ention the interplay of art and science — or, more specifically, any instance of the influence of art on science and perspective is likely to feature prominently. Discovered early in the fifteenth century by the great Florentine architect Filippo Brunelleschi, and first codified in writing by Leon Battista Alberti in his little book On Paintingin 1435, perspective not only became the stock mode of representing any threedimensional form in science and technology, but also played a key role in the development of projective geometry around 1600 and of descriptive geometry two centuries later.

For many artists, perspective assumed the status of a convenient technique a routine geometrical-cum-optical trick to establish the illusion of a space behind the surface of a picture. But for a minority of theoretically inclined artists it acted as a research tool, through which the picture became an experimental field for the geometrical construction of illusions emulating the optical force of real space.

Even more exceptionally, the mastery and use of optical rules could constitute an ethical imperative. The greatest of such artists was the Renaissance painter, Piero della Francesca. Even a quick inspection of his relatively small painting of the Flagellation will reveal the meticulous construction of an exceptionally deep platform, passing back from the zone in which three figures debate the nature of Christ's torment, as disclosed in the middle ground, to a distant piazza. Careful analysis reveals the extremes to which he went to comply with mathematical rigour. For example, the complex tile pattern within the loggia is projected with scrupulous preci-

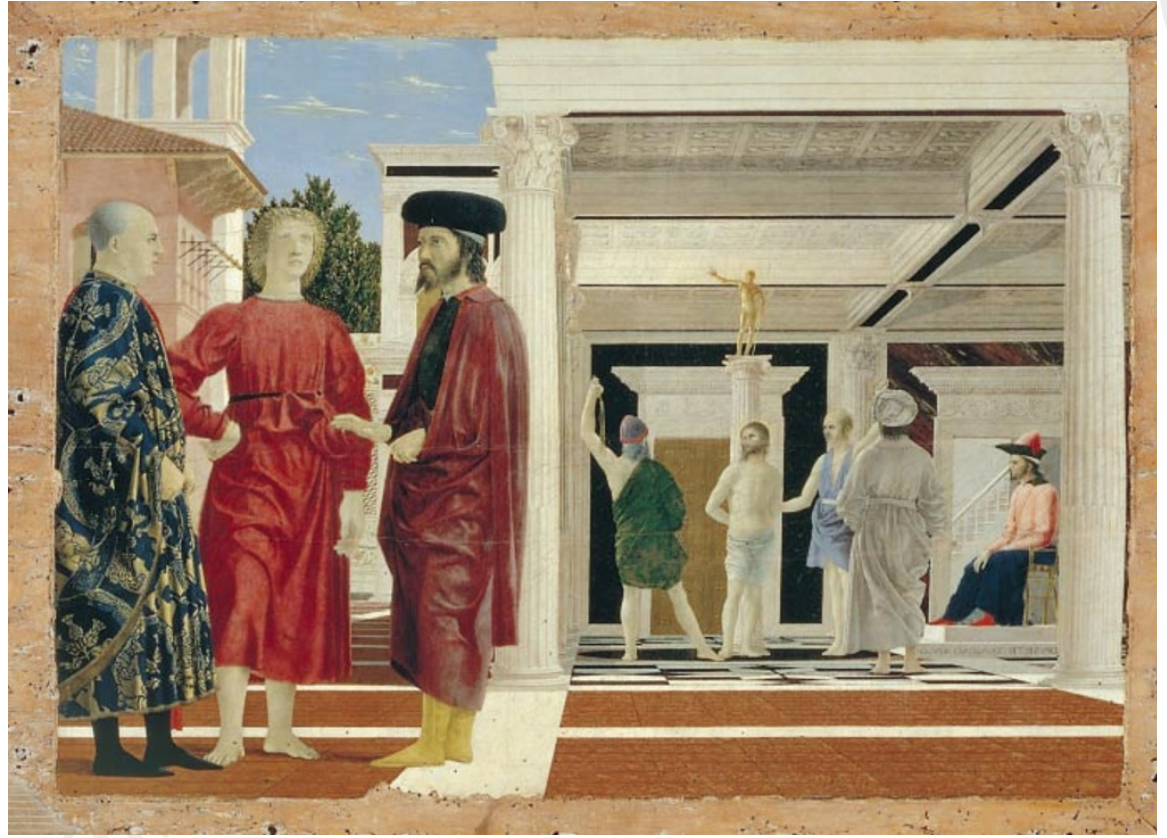

Piero della Francesca, Flagellation, c. 1465.

sion, and is founded upon a series of related squares, the larger of which have side lengths equal to the diagonal of the smaller (i. e. $\sqrt{2}$ ).

Piero wrote books on practical mathematics with simple algebra, on the five regular polyhedra, and, unsurprisingly, on The Perspective of Painting. His treatise on perspective shows how to plot the outlines of forms systematically on to a foreshortened plane, and how to use the plan and elevation of solid bodies to project them point-by-point on to an intersecting plane from a fixed viewpoint. The illustrations below show the first and final stages in the plotting of points disposed in horizontal bands around a head. The final outline results from the coordination of points projected from sections and profile. We know that he followed such meticulous procedures in wall paintings,

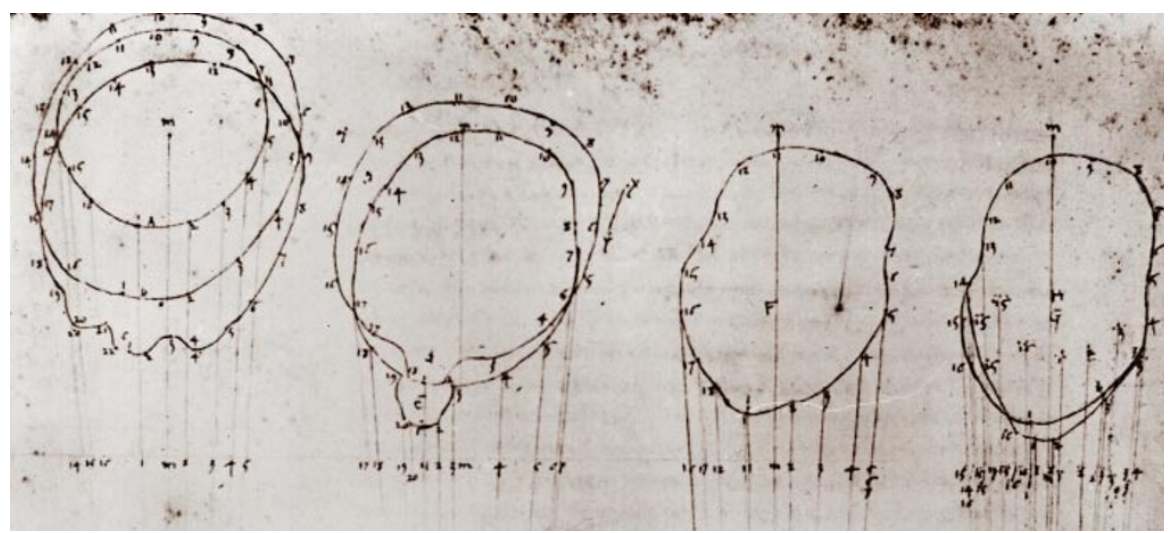

Projection of successive horizontal sections of a head on to picture plane, from Piero della Francesca's The Perspective of Painting.

even when the effects would be so far away from the spectator that they could not be appreciated. Getting things right was integral to his contract with God's design of nature.

But, amid this extreme rationality, he was a painter of miracles, which lie outside optical logic. In the Flagellation the space occupied by Christ, and the section of ceiling above his column, are paradoxically flooded by a burst of light from a source within the architectural space. Only Christ is aware of this miraculous intrusion. It is the very logic of Piero's perspectival consistency that allows him to highlight the supra-normal power of the divine.

Martin Kemp is in the Department of the History of Art, University of Oxford, 35 Beaumont Street,

Oxford OX1 2PG, UK.

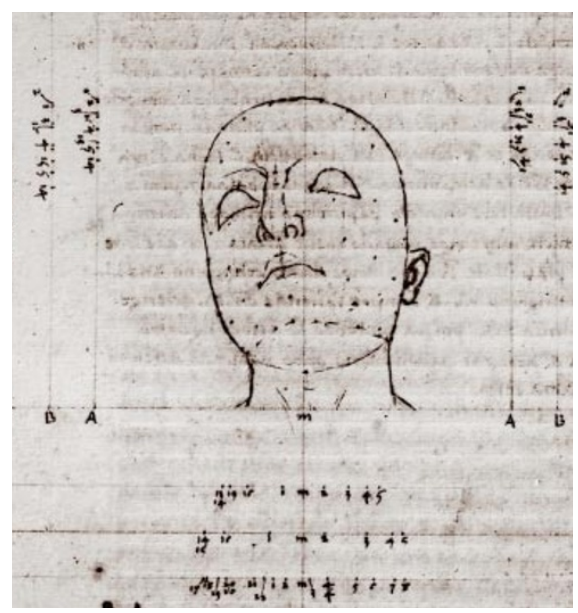

